NASA/TM-2012-217667

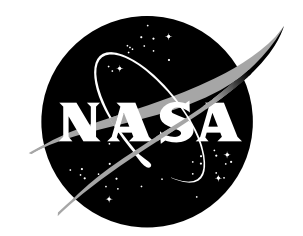

\title{
NASA's Evolutionary Xenon Thruster (NEXT) Power Processing Unit (PPU) Capacitor Failure Root Cause Analysis
}

James F. Soeder, Robert J. Scheidegger, and Luis R. Pinero

Glenn Research Center, Cleveland, Ohio

Arthur J. Birchenough

QinetiQ North America Corporation, Brook Park, Ohio

John W. Dunning

Alphaport, Inc., Cleveland, Ohio 


\section{NASA STI Program . . . in Profile}

Since its founding, NASA has been dedicated to the advancement of aeronautics and space science. The NASA Scientific and Technical Information (STI) program plays a key part in helping NASA maintain this important role.

The NASA STI Program operates under the auspices of the Agency Chief Information Officer. It collects, organizes, provides for archiving, and disseminates NASA's STI. The NASA STI program provides access to the NASA Aeronautics and Space Database and its public interface, the NASA Technical Reports Server, thus providing one of the largest collections of aeronautical and space science STI in the world. Results are published in both non-NASA channels and by NASA in the NASA STI Report Series, which includes the following report types:

- TECHNICAL PUBLICATION. Reports of completed research or a major significant phase of research that present the results of NASA programs and include extensive data or theoretical analysis. Includes compilations of significant scientific and technical data and information deemed to be of continuing reference value. NASA counterpart of peer-reviewed formal professional papers but has less stringent limitations on manuscript length and extent of graphic presentations.

- TECHNICAL MEMORANDUM. Scientific and technical findings that are preliminary or of specialized interest, e.g., quick release reports, working papers, and bibliographies that contain minimal annotation. Does not contain extensive analysis.

- CONTRACTOR REPORT. Scientific and technical findings by NASA-sponsored contractors and grantees.
- CONFERENCE PUBLICATION. Collected papers from scientific and technical conferences, symposia, seminars, or other meetings sponsored or cosponsored by NASA.

- SPECIAL PUBLICATION. Scientific, technical, or historical information from NASA programs, projects, and missions, often concerned with subjects having substantial public interest.

- TECHNICAL TRANSLATION. Englishlanguage translations of foreign scientific and technical material pertinent to NASA's mission.

Specialized services also include creating custom thesauri, building customized databases, organizing and publishing research results.

For more information about the NASA STI program, see the following:

- Access the NASA STI program home page at http://www.sti.nasa.gov

- E-mail your question to help@sti.nasa.gov

- Fax your question to the NASA STI Information Desk at 443-757-5803

- Phone the NASA STI Information Desk at 443-757-5802

- Write to: STI Information Desk NASA Center for AeroSpace Information 7115 Standard Drive Hanover, MD 21076-1320 
NASA/TM-2012-217667

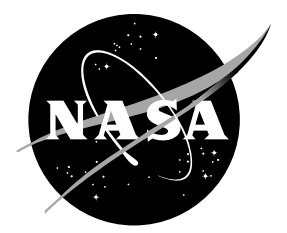

\section{NASA’s Evolutionary Xenon Thruster (NEXT) Power Processing Unit (PPU) Capacitor Failure Root Cause Analysis}

James F. Soeder, Robert J. Scheidegger, and Luis R. Pinero

Glenn Research Center, Cleveland, Ohio

Arthur J. Birchenough

QinetiQ North America Corporation, Brook Park, Ohio

John W. Dunning

Alphaport, Inc., Cleveland, Ohio

Prepared for the

10th International Energy Conversion Engineering Conference (IECEC)

sponsored by the American Institute of Aeronautics and Astronautics

Atlanta, Georgia, July 30 to August 1, 2012

National Aeronautics and

Space Administration

Glenn Research Center

Cleveland, Ohio 44135 
Trade names and trademarks are used in this report for identification only. Their usage does not constitute an official endorsement, either expressed or implied, by the National Aeronautics and Space Administration.

Level of Review: This material has been technically reviewed by technical management.

Available from

NASA Center for Aerospace Information 7115 Standard Drive

Hanover, MD 21076-1320
National Technical Information Service 5301 Shawnee Road Alexandria, VA 22312

Available electronically at http://www.sti.nasa.gov 


\title{
NASA's Evolutionary Xenon Thruster (NEXT) Power Processing Unit (PPU) Capacitor Failure Root Cause Analysis
}

\author{
James F. Soeder, Robert J. Scheidegger, and Luis R. Pinero \\ National Aeronautics and Space Administration \\ Glenn Research Center \\ Cleveland, Ohio 44135 \\ Arthur J. Birchenough \\ QinetiQ North America Corporation \\ Brook Park, Ohio 44142 \\ John W. Dunning \\ Alphaport, Inc. \\ Cleveland, Ohio 44135
}

\begin{abstract}
The NASA's Evolutionary Xenon Thruster (NEXT) project is developing an advanced ion propulsion system for future NASA missions for solar system exploration. A critical element of the propulsion system is the Power Processing Unit (PPU) which supplies regulated power to the key components of the thruster. The PPU contains six different power supplies including the beam, discharge, discharge heater, neutralizer, neutralizer heater, and accelerator supplies. The beam supply is the largest and processes up to $93+\%$ of the power. The NEXT PPU had been operated for approximately 200+ hr and has experienced a series of three capacitor failures in the beam supply. The capacitors are in the same, nominally noncritical location - the input filter capacitor to a full wave switching inverter. The three failures occurred after about 20, 30, and $135 \mathrm{hr}$ of operation. This paper provides background on the NEXT PPU and the capacitor failures. It discusses the failure investigation approach, the beam supply power switching topology and its operating modes, capacitor characteristics and circuit testing. Finally, it identifies root cause of the failures to be the unusual confluence of circuit switching frequency, the physical layout of the power circuits, and the characteristics of the capacitor.
\end{abstract}

\section{Nomenclature}

$\begin{array}{ll}\text { EM } & \text { Engineering Model } \\ \text { ESR } & \text { Equivalent Series Resistance } \\ \text { FRB } & \text { Failure Review Board } \\ \text { GRC } & \text { Glenn Research Center } \\ \text { JPL } & \text { Jet Propulsion Laboratory } \\ \text { MOSFET } & \text { Metal Oxide Semiconductor Field Effect Transistor } \\ \text { MPP } & \text { Molybdenum Permalloy Powder } \\ \text { NEXT } & \text { NASA’s Evolutionary Xenon Thruster } \\ \text { NSTAR } & \text { NASA's Solar Electric Propulsion Technology Application Readiness } \\ \text { PPU } & \text { Power Processing Unit } \\ \text { PWB } & \text { Printed Wiring Board } \\ \text { X7R } & \text { A common type of Barium Titanate dielectric material }\end{array}$




\section{Introduction}

The NASA's Evolutionary Xenon Thruster (NEXT) project is developing an advanced ion propulsion system for future NASA missions for solar system exploration. A critical element of the propulsion system is the power processing unit (PPU) which supplies regulated power to the key components of the thruster. The PPU contains six different power supplies: beam, discharge, discharge heater, neutralizer, neutralizer heater, and accelerator supplies. The beam supply is the largest and processes up to $93+\%$ of the power. After the first 200+ hr of operation, the NEXT PPU experienced a series of three capacitor failures in the beam supply. The capacitors are in the same, nominally non-critical location-the input bypass capacitor to a switching inverter. This paper provides a description of the PPU, including the beam module and its electrical design, discusses the failure including insight into the capacitor design and its characteristics, identifies the approach for determining the root cause including the capacitor testing, and finally describes the initial and long term fixes for the problem.

\section{Description of the PPU}

An engineering model (EM) PPU for the NEXT project was designed and fabricated under contract with NASA Glenn Research Center (GRC). This modular PPU is capable of processing from 0.5 to $7.0 \mathrm{~kW}$ of output power for the NEXT ion thruster. Its design includes many significant improvements for better performance over the state-of-the-art NASA's Solar Electric Propulsion Technology Application Readiness (NSTAR) PPU. The most significant difference is the beam supply which is comprised of six modules and capable of very efficient operation through a wide voltage range because of innovative features like dual controls, module addressing, and a high current mode. The low voltage power supplies are based on the previously validated NSTAR PPU. The highly modular construction of the PPU resulted in improved manufacturability, simpler scalability, and lower cost. A block diagram is shown in Figure 1.

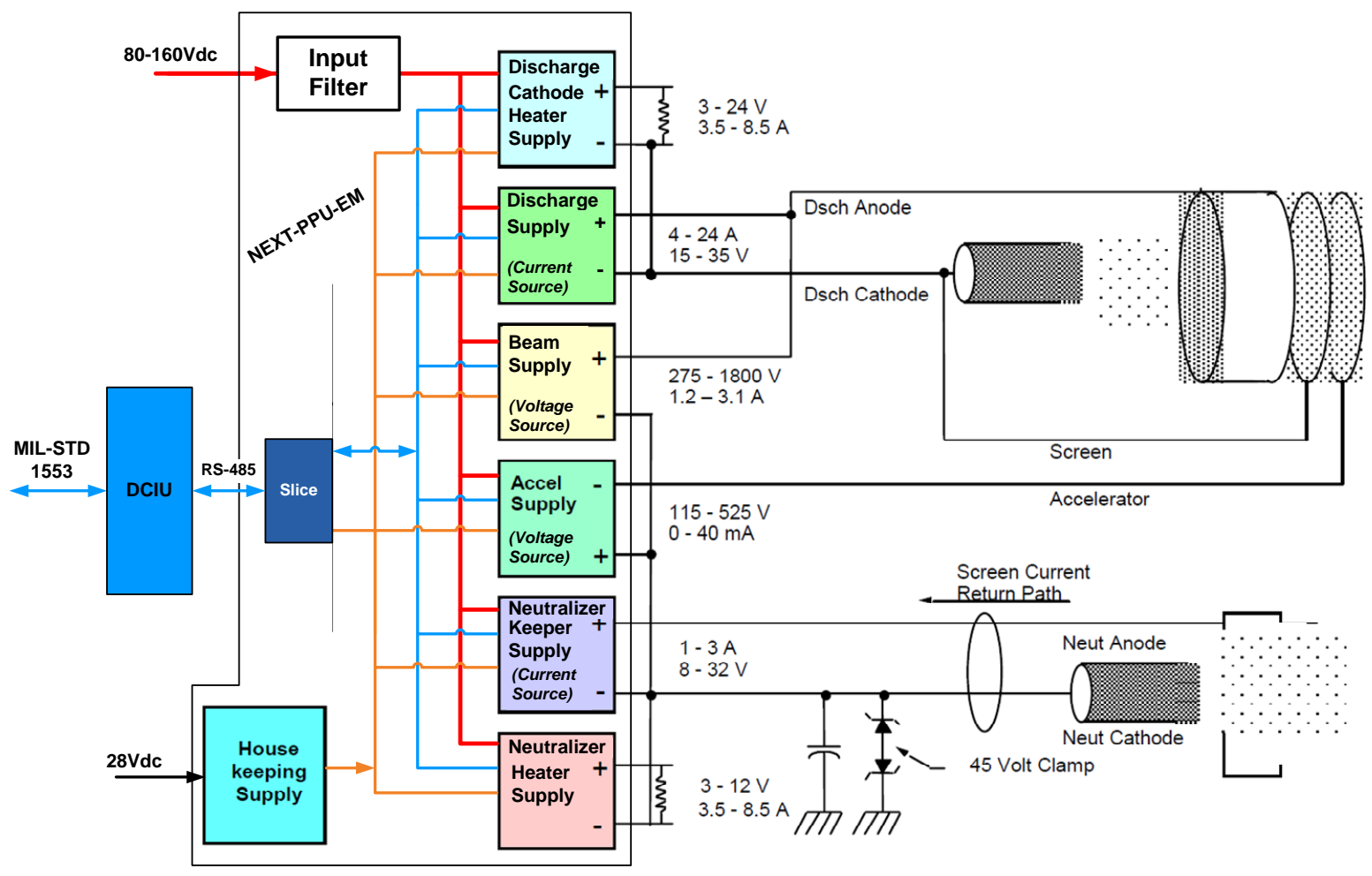

Figure 1.-NEXT-PPU-EM block diagram. 
Of the six power supplies, the most important is the beam supply as it processes up to 93 percent of the thruster power at voltages as high as 1800 VDC. In combination with the accelerator supply, it is used to bias the thruster grids and produce thrust by accelerating the ions generated by the discharge supply. The capacitor failures occurred in the beam supply (Ref. 1).

\section{Description of the Beam Module}

The beam supply consists of six power modules and a master control module. The power modules use an innovative dual-bridge topology that operates in both phase-shift and pulse width modulation modes for efficient operation throughout a wide range of input and output voltages. The modules operate in parallel while the master module controls their operation. A module addressing circuit, selects the number of operational beam modules. At lower power conditions, modules can be turned off to increase efficiency of the beam supply because the housekeeping power consumption is reduced and also the remaining modules can operate closer to optimum load conditions. A current-share circuit balances the current out of each operational beam module. The synchronization of the operational modules is distributed by staggering the clock signals. This inherently reduces ripple on the input and output of the beam supply and helps reduce the size of the input filter. Another feature of the beam supply topology is the capability of operating in a high-current mode where it can output twice the rated current. This mode is operational when the converters operate in pulse-width modulation mode at lower beam outputs voltages with higher input voltages.

Each beam module consists of two main assemblies. The power/regulator assembly contains the primary metal oxide semiconductor field effect transistors (MOSFET) s, input filter, and gate drive circuits. The high voltage assembly contains two power transformers and six output rectifier stages to generate up to $1800 \mathrm{~V}$. Each module can output up to $0.67 \mathrm{~A}$ when operating in phase-shift mode and 1.34 A in "high-current mode."

To accommodate stated mission requirements, the PPU is designed to provide a large voltage range on its output ( 275 to $1800 \mathrm{~V}$ ) independent of a large input voltage range ( 80 to $160 \mathrm{~V}$ ). The beam module bridge circuitry was designed so that the output transformer secondaries are functionally in parallel or in series depending on the sequence of switching the MOSFETs in the two bridges. When the bridges operate in pulse width mode the secondary outputs are effectively in parallel. When the bridges operate in phase mode, the secondary outputs are effectively in series. In phase shift mode, the legs of the two bridges are not switched on and off sequentially and simultaneously but rather in a controlled phase shifted synchronous mode. This mode switching is automatic and is governed by the PPU control circuitry. Figure 2 shows a simplified drawing of the beam supply bridge circuitry. The solid line box indicates the beam module. The filter outside the solid line box is a separate module located some distance from the beam modules in the PPU. The dotted line box indicates the bridge printed wiring board of one beam module. The capacitors of interest are highlighted. The drive circuits for the bridges are clocked at $50 \mathrm{kHz}$.

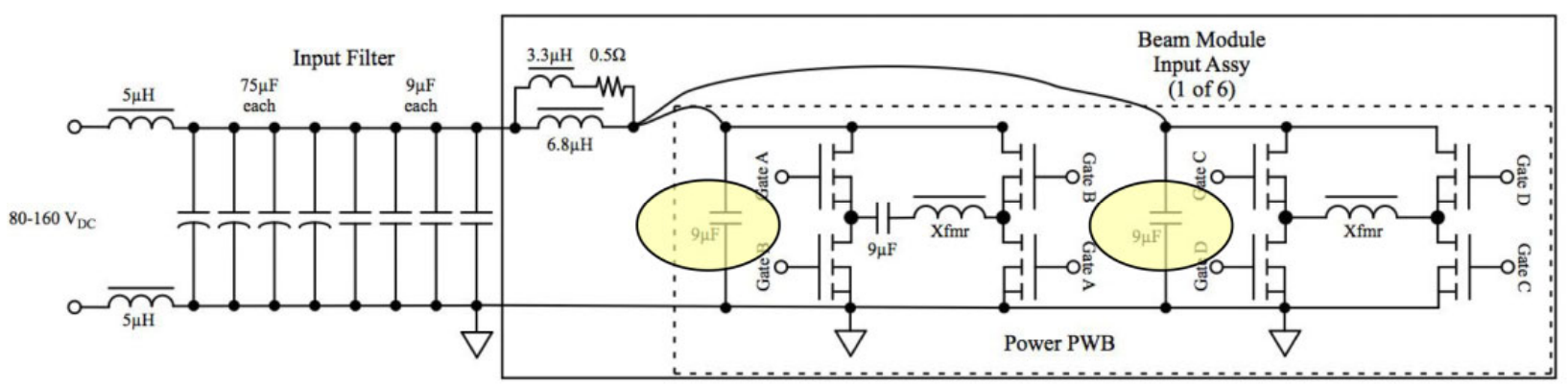

Figure 2.-Simplified schematic of a beam supply. 
The third instance of the $9 \mu \mathrm{F}$ capacitor on the power board is in series with the transformer primary in one of the bridges. This series capacitor is required to eliminate the DC current in the respective transformer. Consequently, the controller can control the DC current in the other transformer. Without the capacitor, the single controller could only control the sum of the DC currents which could be large. Although the currents would sum to zero it would reduce the efficiency of the entire stage.

\section{Description of the Failure}

There have been three failures of a $9 \mu \mathrm{F}$ bypass capacitor in the PPU.

The first failure occurred after about $10 \mathrm{hr}$ of vacuum testing in beam module 1 . It was attributed to incidental impact during assembly. It was theorized that an impact cracked the ceramic capacitor. The crack propagated and exposed electrodes inside the capacitor. Metal migrated through crack and the electrodes eventually shorted causing a catastrophic failure. After circuit analysis, electrical stress was dismissed as possible root cause. The corrective action was to replace the single failed capacitor and resume testing.

The second failure occurred after about 30 additional hours of vacuum testing in beam module 6 . It was attributed to thermal stress during installation of an adjacent component. Electrical stress, arcing, and intrinsic flaws were dismissed or considered unlikely root causes. The corrective action was to replace all 12 beam supply decoupling capacitors. These were replaced at GRC using hand soldering with preheating using a procedure provided by the capacitor manufacturer. The failed capacitor was sent to NASA's Jet Propulsion Laboratory (JPL) for sectioning. The results were inconclusive. As part of the investigation of Failure 2, JPL was asked to assess the possibility of Paschen breakdown contributing to the failure. The assessment indicated that Paschen was an extremely unlike contributor as the vacuum tank pressure was many orders of magnitude below that necessary for a breakdown to occur. Testing was resumed with 12 new (same batch) capacitors in the beam modules.

The third failure occurred in beam module 4 after about $136 \mathrm{hr}$ of operation in a vacuum. The PPU had been burned in for $100 \mathrm{hr}$ at full power in vacuum at $50^{\circ} \mathrm{C}$. The failure occurred while operating with $160 \mathrm{~V}$ input and $820 \mathrm{~W} /$ module output during a forced short circuit to simulate an ion engine fault or recycle. A photograph of the module 4 post failure is included as Figure 3. The failed capacitor and its symmetric mate are bypass capacitors at the input to each of two parallel H-bridge inverters located at each end of the board.

The team assumed that the three failures were of a common root cause, and that the previous findings were not definitive.

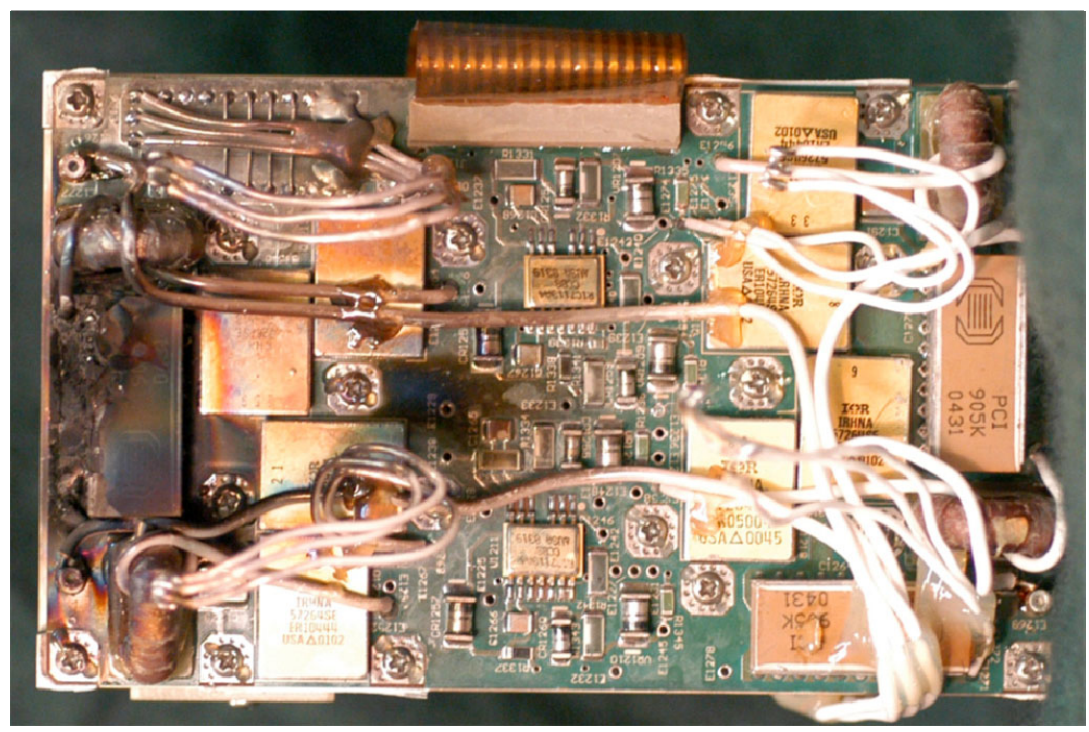

Figure 3.-Photograph of failed beam module power board. 


\section{Failure Investigation Approach}

A Failure Review Board (FRB) was impaneled to determine the root cause of the three failures. A fault tree of possible causes was generated. The uppermost "trunk" of the tree is shown in Figure 4. Each of the five branches was expanded to a point where the implied hypothesis could be analyzed or tested. Each item in the tree was documented with an initial and final assessment and verbiage to document the decision process. Activities were identified for each entry in the fault tree.

After review and completing the activities associated with the detail of each branch, Sections 1 through 4 of the fault tree were eliminated as primary causes of the failures. Below is the synopsis of the investigation.

\section{Section 1-Intrinsic Defects}

Internal and external analysis could find no evidence of intrinsic defects in the capacitors analyzed or tested. Photo-micrographs of the capacitor from the second were examined. Used capacitor removed from the PPU and new capacitors from the same lot used to build the PPU were also sectioned and photographed.

\section{Section 2-Assembly and Handling}

After a review of procedures and thermal data, it was concluded that no items in Section 2 of the fault tree were the primary cause of the failure. While the second failure investigation did identify a weakness in the printed wiring board (PWB) assembly process, this FRB deemed the second failure root cause and corrective action determination to be incorrect.

\section{Section 3-Mechanical Design}

A review of the design and the results of modeling activities eliminated Section 3 as a source of the failure.

\section{Section 4-Operating Environment}

After a review of test procedures, test logs, and thermal data, it was concluded that no items in Section 4 of the fault tree were the primary cause of the failure. Lack of conformal coating in the EM unit to allow access for modifications during testing had been eliminated as a cause during second failure. That finding was upheld by this review.

\section{Section 5-Electrical Design and Operation}

Most of the FRB effort was expended in Section 5 of the fault tree.

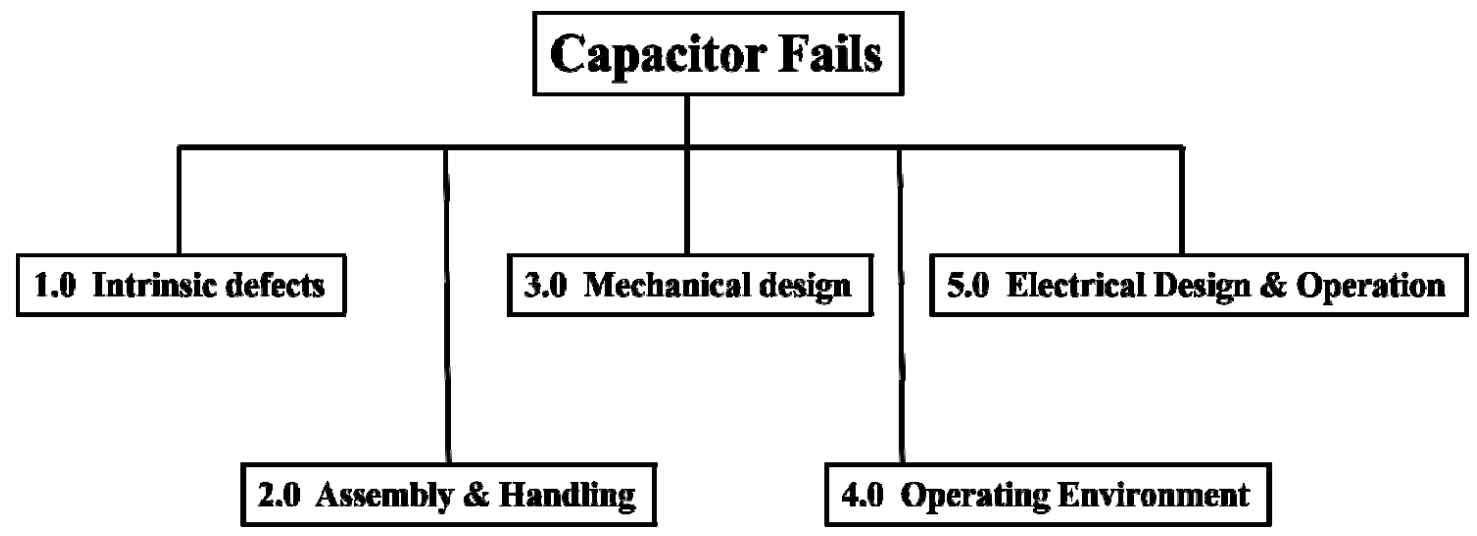

Figure 4.-Top level of the fault tree. 


\section{Electrical Design and Operation}

The majority of the failure investigation effort was expended on the areas in Section 5 of the fault tree. This included examining issues with circuit operation, circuit layout, as well as interactions between the capacitor and the circuit both on a transient and a steady state basis.

In order to evaluate the circuit operation in a relevant environment, measurements were made using beam module 2 which had been extracted from the EM PPU. This allowed the characterization of module operation across the performance envelope. Of particular interest was the voltage on and current through the bypass capacitors shown in shaded ovals in Figure 2. Since the capacitors are hard mounted to the PWB, special instrumentation had to be developed to measure the current. This proved to be very beneficial to discovering one significant contributor to the failure.

To that end, a special current transformer was manufactured that encircled the positive lead of one of the capacitors. With that in place, the ripple current through the capacitor could be measured. With the use of a simple Hall Effect current probe, the circulating current between the two capacitors could be measured. Voltage measurements were relatively easily measured with the module operating in a bench environment. Circulating currents of 16 A peak to peak and ripple currents of 20 A peak to peak were measured while the bridges operate in phase shift mode. While in pulse width mode, no circulating current could be detected. An oscilloscope trace is presented in Figure 5 of the current through one of the decoupling capacitors in module 2 during operation at $90 \mathrm{~V}$ input and $1800 \mathrm{~V}$ output. For these conditions, the bridges are operating in phase shift mode.

Circulating currents of this magnitude leading to large capacitor ripple currents are not desirable and are discussed further in Section IX.

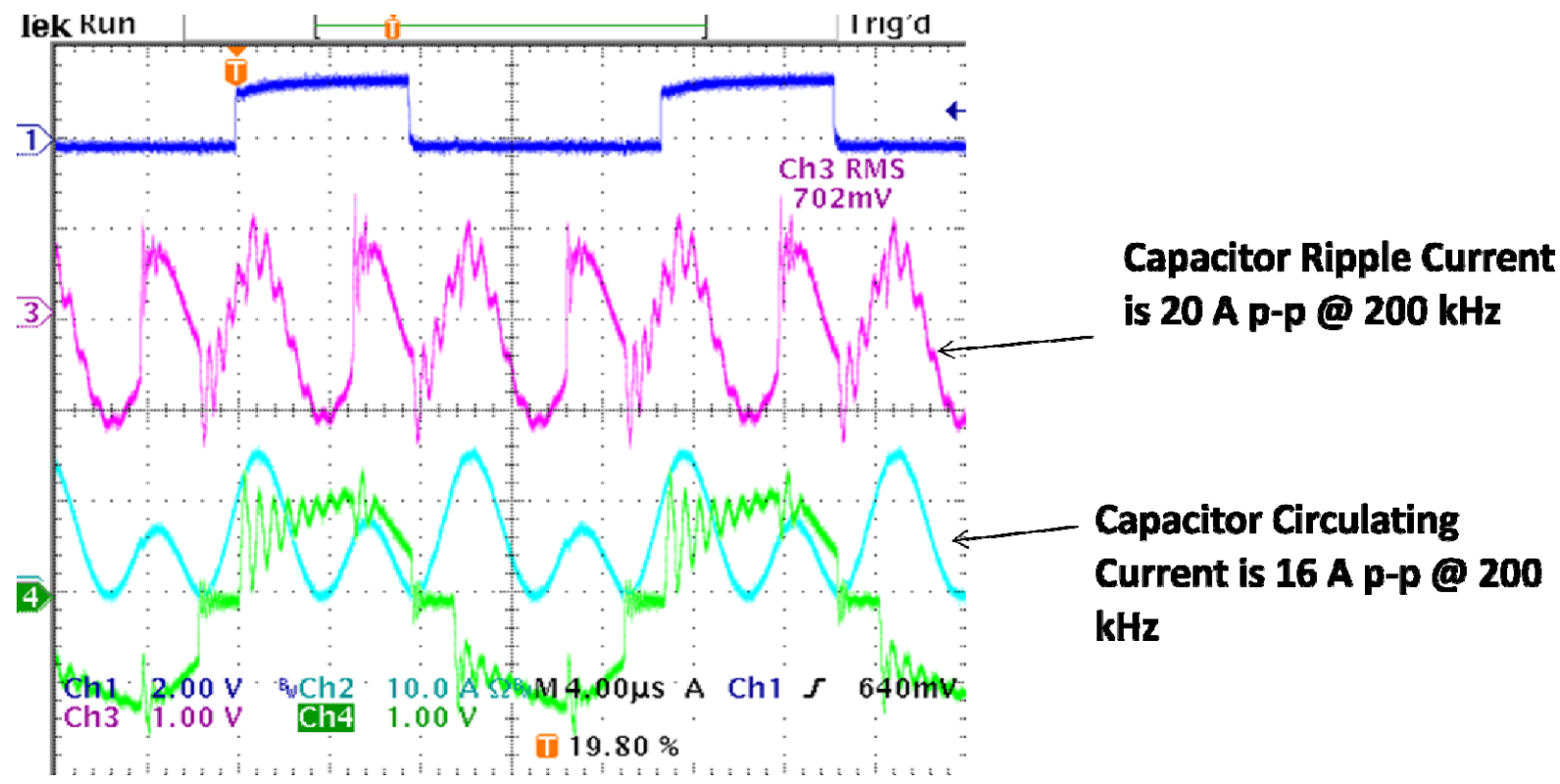

Figure 5.-Capacitor current during normal operation. 


\section{Capacitor Background and Characteristics}

In addition to the evaluating circuit behavior, the capacitors were subjected to analysis. The bypass capacitors are custom $9 \mu \mathrm{F}, 300 \mathrm{~V}$ devices. The same capacitor is used in many other locations in the PPU.

Ceramic capacitors are constructed with alternating layers of a metal electrode and a ceramic insulator that functions as the dielectric. Barium Titanate is a typical dielectric material available in a variety of temperature coefficients like X7R. Barium Titanate is a ferroelectric material which give the proper conditions can exhibit the piezoelectric effect. In some cases, the piezoelectric effect may result in the appearance of electrical noise, while in other cases; an acoustic sound may be heard, coming from the capacitor itself.

The properties of the Barium Titanate can be modified with dopants like Niobium and Strontium to tailor the electrical and mechanical properties for an application. However, the slightest alternation can modify the acuteness of the piezoelectric response in the ceramic material.

Another phenomenon found in ferroelectric ceramic capacitors is that the value of capacitance decreases with applied DC voltage. In "voltage stabilized" ceramic capacitors, the formulation of the dielectric materials is slightly modified to compensate for the effect. Consequently, their capacitance falls only a few percent at rated voltage. The capacitors that failed in this PPU were not voltage stabilized and lost about half of their rated capacitance at 2/3 of rated voltage (Refs. 2 and 3).

\section{Capacitor Evaluation and Testing}

At the start of this activity only 25 of the 90 custom capacitors were available for use in this investigation. Histories were compiled of the life events of those capacitors that had seen some use. Since the population of unused capacitors was small, no statistically significant testing could be accomplished. Each use of a capacitor was carefully considered to yield as much information as possible.

In evaluating the capacitors, the FRB discovered that the Barium Titanate dielectric formulation used in these capacitors is highly piezoelectric. Application of voltage at slightly elevated temperatures will permanently polarize the capacitor. A polarized capacitor will have internal resonances that are inversely proportional to the case dimensions and proportional to the speed of sound in the ceramic. For these capacitors at room temperature the width resonance is at $186 \mathrm{KHz}$ and the length resonance is at $75 \mathrm{kHz}$. As the temperature rises, the resonance frequency also rises. Application of temperature without voltage depolarizes the capacitor.

A little known or forgotten phenomena associated with ceramic capacitor piezoelectric properties is that the electrical properties (capacitance, impedance, equivalent series resistance (ESR), phase, etc.) change by orders of magnitude in the neighborhood of the piezoelectric resonances. The discontinuities in the impedance plot shown in Figure 6 are associated with the width and length mechanical resonances.

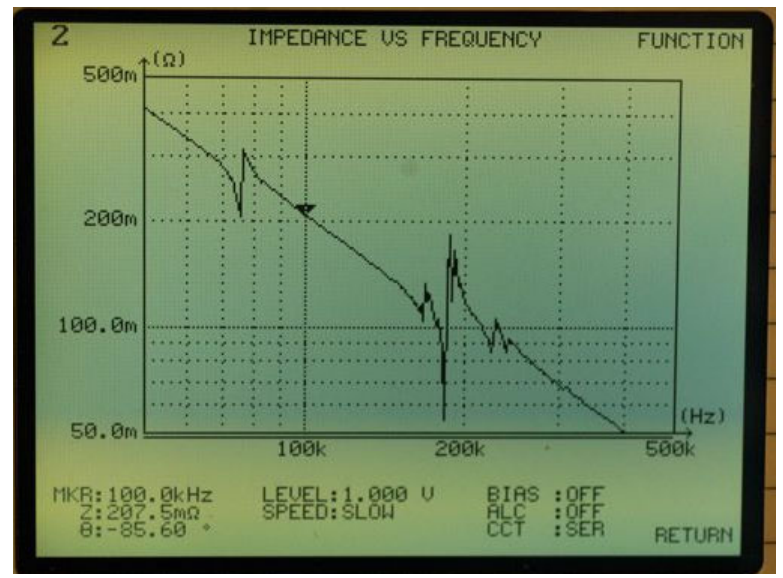

Figure 6.-Impedance sweep of failed capacitor prior to failure. 
In capacitor characterization testing conducted at GRC, every virgin capacitor could be poled to the same impedance versus frequency characteristics shown in Figure 6 after exposure to modest temperatures and voltage bias (above $50^{\circ} \mathrm{C}$ and $150 \mathrm{~V}$ ). A decoupling capacitor run in a module on a bench-top was also found to be poled after module operation at $160 \mathrm{~V}$ and in a room temperature environment.

Since the PPU runs above ambient temperature and input voltage is always connected, the decoupling capacitors are always polarized. Consequently, the capacitors are subject to mechanical actuation if they are excited at or near the frequencies where the discontinuities occur.

\section{High Level Test Results}

In order to understand effects of the circuit on the capacitors, it was important to measure current and voltage in, through, and around the decoupling capacitors. To that end, a special current transformer was manufactured that encircled the positive lead of one of the capacitors. With that in place, the ripple current could be measured at the point indicated in Figure 7. With the use of a simple Hall Effect current probe, the circulating current could be measured at the point indicated in Figure 7 . Scope traces of these currents were shown previously in Figure 5 . Voltages were relatively easily measured with the module operating on in a bench environment. As indicated previously, currents of 16 A peak to peak were measured while the bridges operate in phase shift mode caused by an electrical resonance at a frequency of $200 \mathrm{KHz}$ between the $9 \mathrm{uF}$ capacitors and inductance of the wires that connect them to the input inductor in the module. It is this circulating current at $200 \mathrm{kHz}$, interacting with the capacitor piezoelectric resonance and the circuit self resonance that causes the capacitor to fail. Note: While in pulse width mode, there is essentially no circulating current.

Resonances were measured in several spare capacitors. The capacitors had piezoelectric resonances at 75 and $186 \mathrm{kHz}$ corresponding to the length and width of the device. The resonant frequencies are temperature dependent causing them to shift higher under operation. Independent testing confirmed orders of magnitude changes in the capacitor ESR at the resonances. As a test frequency was swept through the resonance, the phase angle between the current and voltage changed from +90 (capacitive leading) to 0 (resistive) to -90 (inductive - lagging) and then back to +90 .

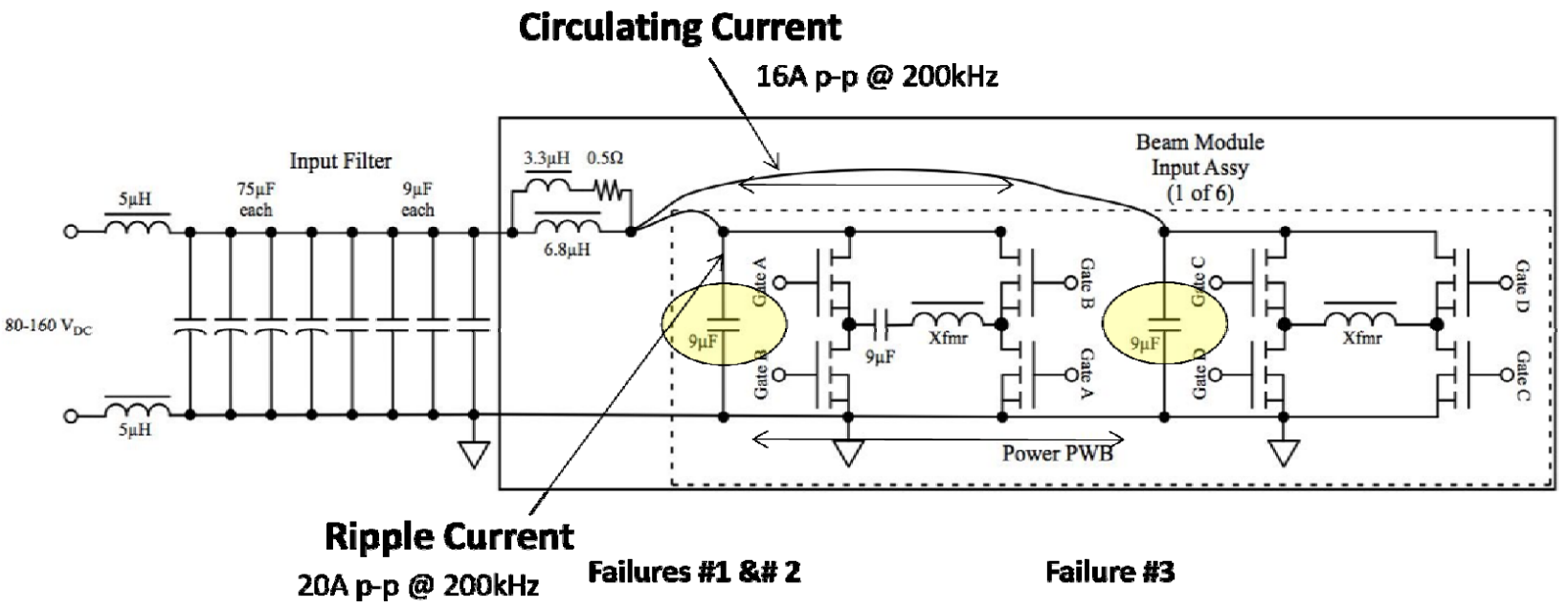

Figure 7.-Beam module dual bridge schematic. 


\section{Electrical Testing}

A number of circuits were created to simulate in-circuit electrical conditions on an isolated capacitor. Circuits simulated the circulating current, the current spikes at shutdown and their combined effect.

Shown below is a trace showing the behavior of the capacitor with the simulated circulating current. The expected behavior at this point is the current should be leading the voltage by about $70^{\circ}$. However, as the frequency of the circulating current approaches the resonance near $200 \mathrm{kHz}$, the voltage/current phase relationship changes until they are in phase which indicates that the capacitor is behaving as a resistor. Coincidentally, the temperature in the capacitor increases considerably reaching $84^{\circ} \mathrm{C}$ because a large amount of power is being dissipated in the capacitor. The waveform for a $200 \mathrm{kHz}$ drive frequency is shown in Figure 8.

Exercising the capacitors using these test circuits resulted in repeated failures. Figure 9 shows the results of one of the failures. For the first $340 \mathrm{hr}$ operation the data had been exactly as shown on the left side of the plot. The failure mechanism is as follows. At about 1:00 a.m. a micro-crack caused the total current to increase and the temperature swings to decrease. For the next $10 \mathrm{hr}$ the current remained steady as the temperature slowly increased. During this time electrode metal was migrating into the micro-crack. Finally at 11:15 a.m., enough metal had migrated to create a short circuit across the capacitor electrodes which dumped all of the energy in the circuit and destroyed the capacitor.

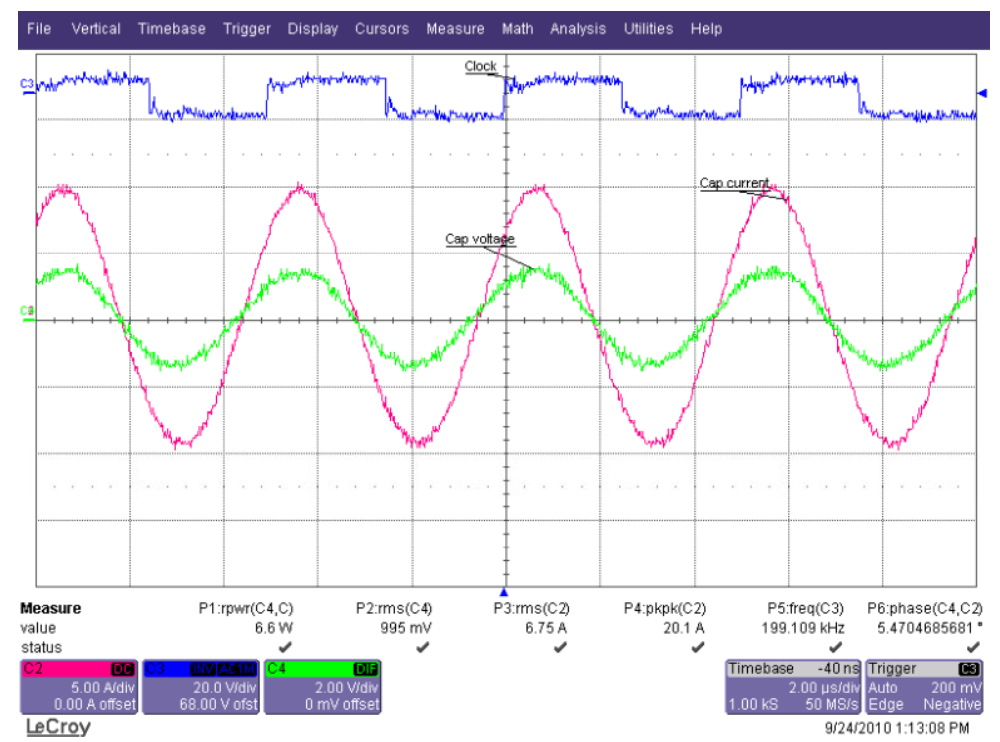

Figure 8.-Current and voltage trace during growler test-200 kHz.

\section{Day of Failure Recorded Temp \& Current}

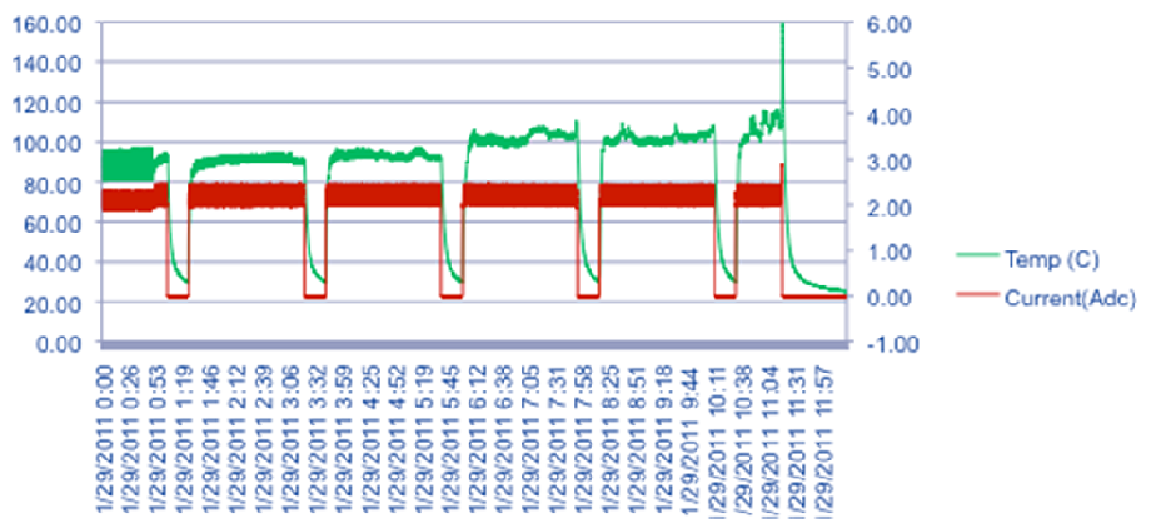

Figure 9.-Data log for third FRB capacitor failure. 


\section{Analysis}

Analytic models of the beam module inverter, master control, and beam module control, and secondary output boards were created and exercised. These models provided analytic measurements at circuit locations that are inaccessible in the PPU. The models also provided assurance that the recommended modifications would function appropriately. A thermal model of the capacitor and the power regulator assembly was created to verify capacitor temperature and various operating conditions. This model was validated by thermocouple measurements in the PPU.

One of the more interesting modeling results is the prediction of a resonance between the two decoupling capacitors with the inductance of the short length of wire from each capacitor to the common beam module input filter. Using measured values of the wire inductance $(260 \mathrm{nH})$, circulating currents over 20 A peak to peak at $200 \mathrm{kHz}$ were predicted using the inverter model. If the inductance of the wire were to change, the resonant frequency would change accordingly. Since the capacitance is a function of both temperature and voltage, the electrical resonant frequency could move to the $200 \mathrm{kHz}$ and excite the mechanical piezoelectric resonance.

\section{Root Cause Summary}

\section{A. Circuit Resonance}

The two bypass capacitors in the beam module inverters and the lengths of wire connecting them to the input filter form a resonant circuit. When the beam module is operated in phase-shift mode, a circulating current of $16 \mathrm{~A}$ at $200 \mathrm{kHz}$ flows through the capacitors. This was confirmed by measurements and electrical models.

\section{B. Circulating Current}

When the beam module is operating in phase mode to get higher output voltages at lower input voltages the two bridges are driven synchronously but out of phase with the phase shift proportional to the output voltage. Since the two bridges are connected to a common point at the input filter, it is possible to force currents to flow back and forth between the two capacitors at $4 \mathrm{x}$ the drive frequency $(200 \mathrm{kHz})$.

In testing an individual beam module that had been removed from the PPU, a large circulating current was measured between the two capacitors while the two bridges were operating in phase mode. The circulating current had a frequency of four times the bridge switching frequency-about $200 \mathrm{kHz}$.

\section{Capacitor Characteristics}

It was found that the capacitors have a piezoelectric resonance at about $187 \mathrm{kHz}$. As the capacitor warms, this resonance drifts higher in frequency.

Under the right conditions of temperature and voltage, all three phenomena overlap and the capacitor suffers a catastrophic failure. This root cause hypothesis is believed to be the cause of all three capacitor failures during PPU testing.

\section{Resolution}

A permanent solution to the capacitor failure problem would require redesign of the beam module. In order to facilitate continued testing of the PPU, an interim fix has been implemented. The circulating current between the inverters has been reduced by the addition of a Molybdenum Permalloy Powder (MPP) Core into the leads from the input filter inductor in the module to the capacitors, forming a differential mode choke. In addition, the decoupling capacitors were replaced with capacitors that do not demonstrate significant piezoelectric activity and cannot be permanently polarized. 


\section{Conclusions}

The PPU was designed to meet a set of requirements levied by the In-Space Propulsion Technology project. Portions of those requirements include being able to operate over a wide range of input voltage (80 to $160 \mathrm{~V}$ ) while producing a wide range of output voltages (275 to $1800 \mathrm{~V}$ ). In addition, constraints were placed on PPU mass and efficiency. The resultant design is an elegant solution to the problem but sets the stage for the capacitor failures.

In order to accommodate both the input and output voltage ranges, a clever circuit was introduced into the beam supply that provided pulse width modulation for two paralleled inverters in each beam module for higher input voltages and lower output voltages. The control system switches the two bridges to a phaseshift mode of operation for lower input voltages and higher output voltages. During phase-shift operation the two inverters pump current back and forth at approximately the same frequency as the piezoelectric resonance in the capacitors $(200 \mathrm{kHz})$. In addition, the two capacitors with the connecting wiring form an electrical resonant circuit near $200 \mathrm{kHz}$. Since both the mechanical and electrical resonant frequencies are functions of temperature, it is possible for both resonances to align at $200 \mathrm{kHz}$. This will lead to internal heating. The internal heating accompanied by the piezoelectric motion in the width direction leads the development of internal micro-cracks. Internal micro-cracks with the slightly elevated temperatures lead to electrode metal migration which ultimately leads to an internal short circuit and part failure.

The corrective actions outlined in Section XIII that included adding an MPP core and replacing the capacitor with one that cannot be easily polarized have been implemented. Further testing has demonstrated that these fixes have successfully resolved the problem.

\section{References}

1. Pinero, L.R., Hopson, M., Todd, P.C., Wong, B., "Performance of the NEXT Engineering Model Power Processing Unit,” NASA/TM-2007-215037, AIAA Paper-2007-5214, E-16217.

2. Boser, O., Kellawon, P., Geyer, R., "Electromechanical Resonances in Ceramic Capacitors and Their Use for Rapid Nondestructive Testing,” Journal of the American Ceramic Society, Vol. 72, No. 12, 1989, pp. 2282-2286.

3. Boser, O., Kellawon, P., Geyer, R., "Rapid Nondestructive Testing of Ceramic Multilayer Capacitors," Components, Hybrids, and Manufacturing Technology, IEEE Transactions on, Vol. 12, No. 1, March 1989, pp. 121-123. 


\begin{tabular}{|c|c|c|}
\hline \multicolumn{2}{|c|}{ REPORT DOCUMENTATION PAGE } & $\begin{array}{l}\text { Form Approved } \\
\text { OMB No. 0704-0188 }\end{array}$ \\
\hline \multicolumn{3}{|c|}{ 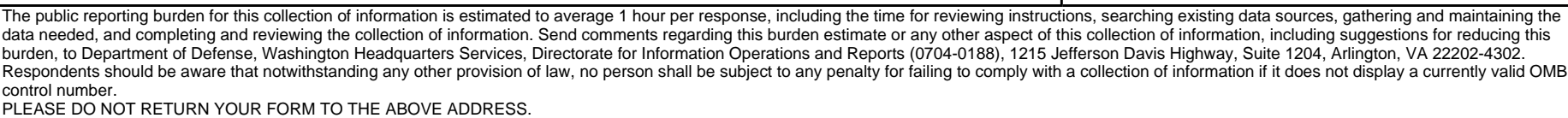 } \\
\hline $\begin{array}{l}\text { 1. REPORT DATE (DD-MM-YYYY) } \\
01-08-2012\end{array}$ & $\begin{array}{l}\text { 2. REPORT TYPE } \\
\text { Technical Memorandum }\end{array}$ & 3. DATES COVERED (From - To) \\
\hline \multirow{3}{*}{\multicolumn{2}{|c|}{$\begin{array}{l}\text { 4. TITLE AND SUBTITLE } \\
\text { NASA’s Evolutionary Xenon Thruster (NEXT) Power Processing Unit (PPU) Capacitor } \\
\text { Failure Root Cause Analysis }\end{array}$}} & 5a. CONTRACT NUMBER \\
\hline & & 5b. GRANT NUMBER \\
\hline & & 5c. PROGRAM ELEMENT NUMBER \\
\hline \multirow{3}{*}{\multicolumn{2}{|c|}{$\begin{array}{l}\text { 6. AUTHOR(S) } \\
\text { Soeder, James, F.; Scheidegger, Robert, J.; Pinero, Luis, R.; Birchenough, Arthur, J.; } \\
\text { Dunning, John, W. }\end{array}$}} & 5d. PROJECT NUMBER \\
\hline & & 5e. TASK NUMBER \\
\hline & & $\begin{array}{l}\text { 5f. WORK UNIT NUMBER } \\
\text { WBS 346620.04.08.02.02.01 }\end{array}$ \\
\hline \multicolumn{2}{|c|}{$\begin{array}{l}\text { 7. PERFORMING ORGANIZATION NAME(S) AND ADDRESS(ES) } \\
\text { National Aeronautics and Space Administration } \\
\text { John H. Glenn Research Center at Lewis Field } \\
\text { Cleveland, Ohio 44135-3191 }\end{array}$} & $\begin{array}{l}\text { 8. PERFORMING ORGANIZATION } \\
\text { REPORT NUMBER } \\
\text { E-18344 }\end{array}$ \\
\hline \multirow{2}{*}{\multicolumn{2}{|c|}{$\begin{array}{l}\text { 9. SPONSORING/MONITORING AGENCY NAME(S) AND ADDRESS(ES) } \\
\text { National Aeronautics and Space Administration } \\
\text { Washington, DC 20546-0001 }\end{array}$}} & $\begin{array}{l}\text { 10. SPONSORING/MONITOR'S } \\
\text { ACRONYM(S) } \\
\text { NASA }\end{array}$ \\
\hline & & $\begin{array}{l}\text { 11. SPONSORING/MONITORING } \\
\text { REPORT NUMBER } \\
\text { NASA/TM-2012-217667 }\end{array}$ \\
\hline \multicolumn{3}{|c|}{$\begin{array}{l}\text { 12. DISTRIBUTION/AVAILABILITY STATEMENT } \\
\text { Unclassified-Unlimited } \\
\text { Subject Category: } 33 \\
\text { Available electronically at http://www.sti.nasa.gov } \\
\text { This publication is available from the NASA Center for AeroSpace Information, 443-757-5802 }\end{array}$} \\
\hline
\end{tabular}

\section{SUPPLEMENTARY NOTES}

\section{ABSTRACT}

The NASA's Evolutionary Xenon Thruster (NEXT) project is developing an advanced ion propulsion system for future NASA missions for solar system exploration. A critical element of the propulsion system is the Power Processing Unit (PPU) which supplies regulated power to the key components of the thruster. The PPU contains six different power supplies including the beam, discharge, discharge heater, neutralizer, neutralizer heater, and accelerator supplies. The beam supply is the largest and processes up to 93+\% of the power. The NEXT PPU had been operated for approximately 200+ hr and has experienced a series of three capacitor failures in the beam supply. The capacitors are in the same, nominally non-critical location-the input filter capacitor to a full wave switching inverter. The three failures occurred after about 20,30, and $135 \mathrm{hr}$ of operation. This paper provides background on the NEXT PPU and the capacitor failures. It discusses the failure investigation approach, the beam supply power switching topology and its operating modes, capacitor characteristics and circuit testing. Finally, it identifies root cause of the failures to be the unusual confluence of circuit switching frequency, the physical layout of the power circuits, and the characteristics of the capacitor.

\section{SUBJECT TERMS}

Power converters; Capacitors; Power conditioning

\begin{tabular}{|c|c|c|c|c|c|}
\hline \multicolumn{3}{|c|}{ 16. SECURITY CLASSIFICATION OF: } & \multirow{2}{*}{$\begin{array}{l}\text { 17. LIMITATION OF } \\
\text { ABSTRACT } \\
\text { UU }\end{array}$} & \multirow{2}{*}{$\begin{array}{l}\text { 18. NUMBER } \\
\text { OF } \\
\text { PAGES } \\
17\end{array}$} & \multirow{2}{*}{$\begin{array}{l}\text { 19a. NAME OF RESPONSIBLE PERSON } \\
\text { STI Help Desk (email:help@sti.nasa.gov) } \\
\text { 19b. TELEPHONE NUMBER (include area code) } \\
\text { 443-757-5802 }\end{array}$} \\
\hline $\begin{array}{l}\text { a. REPORT } \\
\text { U }\end{array}$ & $\begin{array}{l}\text { b. ABSTRACT } \\
U\end{array}$ & $\begin{array}{l}\text { c. THIS } \\
\text { PAGE } \\
\text { U }\end{array}$ & & & \\
\hline
\end{tabular}


